\title{
Protected Areas and Community Relationships in the Sub-Saharan Africa: A case study of Dwesa- Cwebe Nature Reserve in the Eastern Cape, South Africa
}

\author{
Andisiwe Bango, Zanele Xelelo \\ Walter Sisulu University \\ Nelson Mandela Drive, Mthatha, South Africa \\ abango@wsu.ac.za
}

\begin{abstract}
Protected areas represent the heart of the world's political and economic commitment to preserve biodiversity and other natural and related cultural resources. Ecologists and conservation biologists believe that among the practical ways of protecting biodiversity is through reserves, parks, wildlife sanctuaries, wilderness and other protected areas. In the Sub- Saharan Africa, unsustainable resource use and increasing human population threaten protected areas as most African rural communities depend on accessing resources found in protected areas: wood, wild fruits and game as a livelihood strategy. As a result, in total, Africa contains 1254 protected areas including 198 marine protected areas, 50 biosphere reserve, 80 wetlands of international importance and 34 world heritage sites. The success of long-term existence of protected areas depends on local people's support and understanding of what protected areas advocate for. To get an understanding of the complex relationships between protected areas and adjacent communities, the study was undertaken at Dwesa- Cwebe Nature Reserve in the Eastern Cape in South Africa. The aim of the study was to assess the relationship between Eastern Cape Parks and the adjacent communities at Dwesa-Cwebe Nature Reserve.

A sample size of 120 respondents sampled from four villages (Cwebe, Hobeni, Ntlangula and Ntubeni) that are within 10- $15 \mathrm{~km}$ because they are the ones mostly affected positively or negatively by the reserve. In each of the four villages the researcher sampled 30 respondents. The study found that conflicts between protected areas and communities are due to resource extraction, strict rules on forest resources use, and access, rude behaviour, or harassment by park rangers generate negative attitudes toward protected areas.
\end{abstract}

\section{Introduction}

The United Nation Environment Programme (2002) defines protected areas as areas of land and or sea especially dedicated to the protection and maintenance of biological diversity and of natural and associated cultural resources, managed through legal or other effective means. The success of conservation through protected area is influenced by the ability of reserve managers to reconcile biodiversity conservation goals with social and economic issues. (Andrade and Rhodes, 2012) In the Sub- Saharan Africa, protected areas face numerous challenges from adjacent communities, particularly in remote rural communities where natural resources dependency is a key livelihood strategy. The increase in population size has led to an increase in the demand for natural resources, which led to the establishment of protected areas to minimise the risk of wildlife extinction from over-use.

Despite the fact that there has been a significant increase in interest in the sustainable management of protected areas, many of them still fail to meet the needs of the adjacent communities. The study was undertaken in the Eastern Cape in the Dwesa- Cwebe Nature Reserve, a marine protected area and four adjacent rural communities to establish the resource access dynamics by the adjacent communities. in South Africa marine protected areas are proclaimed in terms of section 43 of the Marine Living Resources Act 18 of 1998 (MLRA), which regulates both the exploitation and conservation of marine living resources (Tunley,2009). The problem in Dwesa-Cwebe begins with the right to access resources in the forest and the marine ecosystem that is restricted to the adjacent communities. The mandate of protected areas is to preserve biodiversity for future generations but it deprives the right to indigenous people to access the resources that they use to access before the establishment of the reserve.

In the Sub-Saharan Africa, increased demands for timber and non-timber forest products, is the main reason why relatively large forested areas have been subjected to overexploitation, degradation and destruction. A low level of awareness regarding legal issues and nature reserve's management practices is also associated with negative attitudes toward the reserve. Many households were removed from the areas when the nature reserve was introduced and most of 
them the forest and the ocean were their main resources. Rural communities living on areas surrounding protected areas are among the least developed communities of the world and poverty, disempowerment and population pressure are the main issues in these communities (Shikolokolo, 2010).

\section{The Establishment of Protected Areas in Africa}

The establishment of protected areas in Africa has its roots in the hunting ethos natural history studies that were popular at the end of the $18^{\text {th }}$ and the beginning of the $19^{\text {th }}$ centuries in the western world (Tessema et al, 1994). The interests and concerns of the local African people were not considered in the establishment of the protected areas. As Mackenzie (1988) rightly argues, foreign interests and not the interests of the African peoples influenced the legislation for wildlife management and protected areas in particular. In many incidents, creation of these protected areas deprived local people of resources that they had been accessing for a long time, for both their cultural and economic values (Barrow and Murphree, 2001). The approach of establishing and managing protected areas could partly explain the unsympathetic behaviours toward wildlife management in Africa by local people (Mugisha, 2002). The increased pressure on land resources increases the conflicts between protected areas managers and neighbouring communities (Tessema et al, 2010).

Gibson (1999) states that post- colonial African governments also continued to implement conservation policies that excluded local communities as an approach to managing protected areas in Africa. Local communities which used to have access to wildlife resources were excluded from the established protected area management (Mugisha, 2002). Local community members, in efforts to secure their means of survival, were the majority of culprits of this wildlife management set up, and it caused much tension and conflicts between protected areas managers and local people (Borrini-Feyerabend et al, 2004). Serious conflicts would arise where some of the communities claimed traditional access right to resources in protected areas, such as the Balabaig and the Maasai in Tanzania and Kenya (Lane 1996).

To highlight the complexity of the relationship between protected areas and adjacent communities in the Sub-Saharan Africa, a study carried out by Mbaiwa (2005) in Botswana, shows that there is a resource conflict between the Department of wildlife and National Parks in Botswana. The management of Moremi Game Reserve ( a protected area) and the Khwai community in the Okavango Delta. The results of the study indicate that the conflict started by removal of the Khwai community from their ancestral land for the establishment of Moremi Game Reserve. Mbaiwa (2005) concluded that the interviews with the head of the household at Khwai community show that they were remarked against their will.

\section{Community Involvement in the Management of Dwesa- Cwebe Nature Reserve}

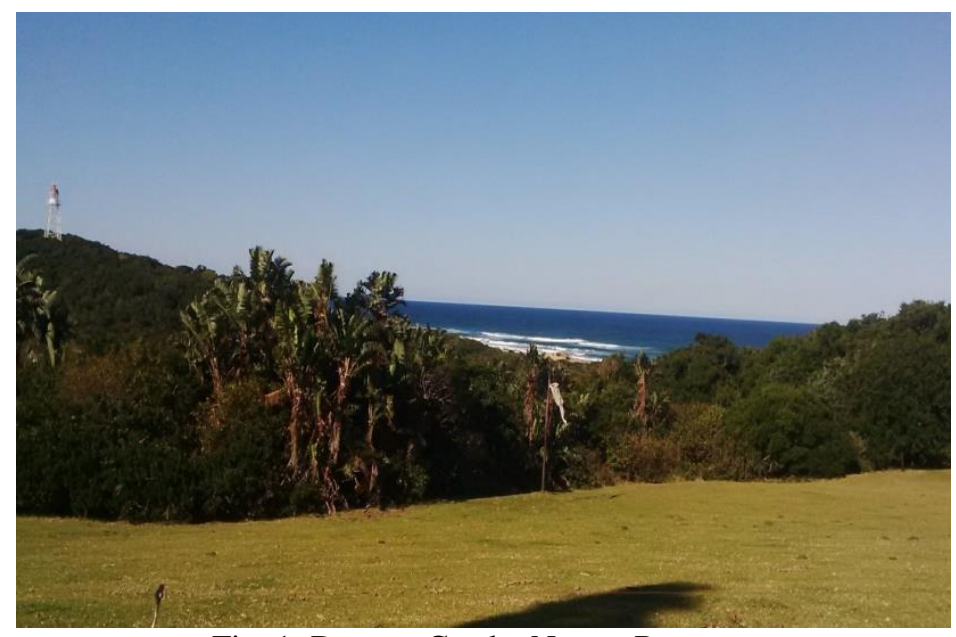

Fig. 1: Dwesa- Cwebe Nature Reserve. 


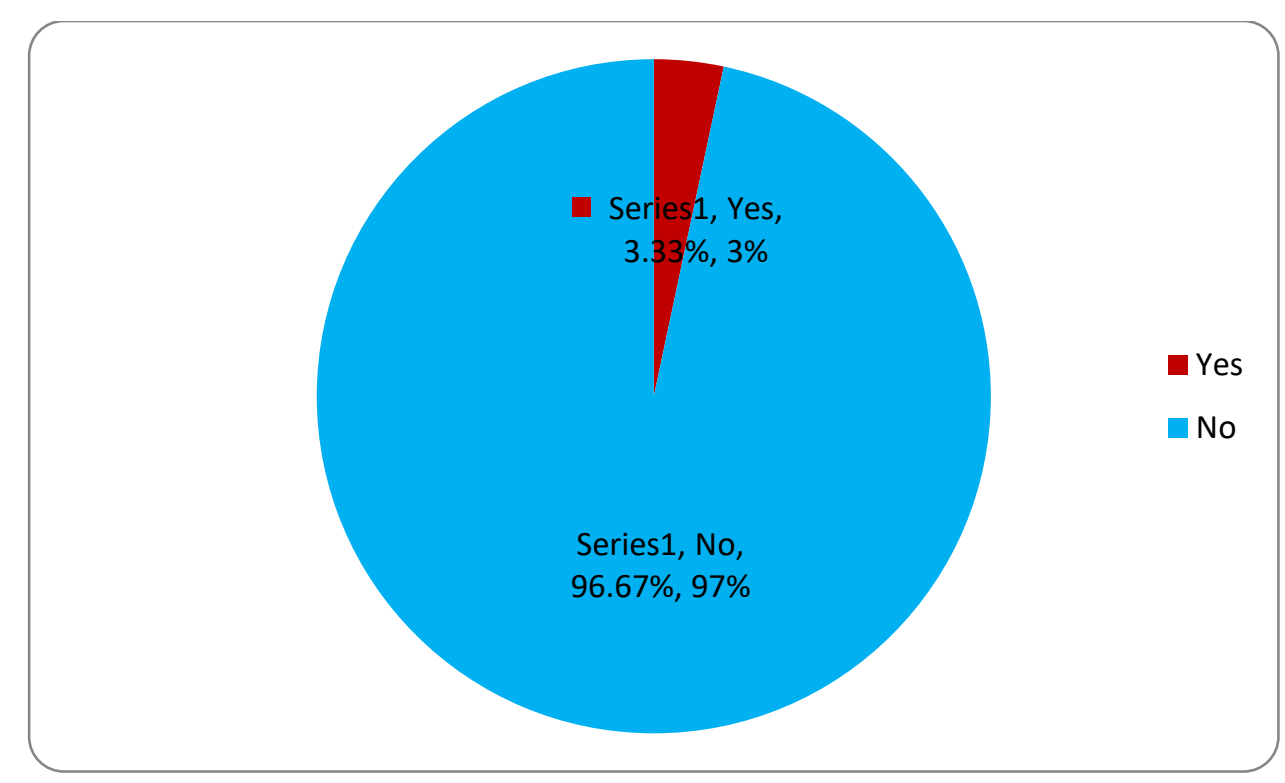

Fig. 2: Community involvement in the management of the reserve.

Data from respondents of the four villages around the Dwesa-cwebe Nature Reserve shows that $97 \%$ of the population are not involved in the management of the reserve. The community members are not included in the decision makings of the reserve. The community views are not included in the decision around resource use in the nature reserve. Respondents were asked to state the level of satisfaction with Dwesa-Cwebe Nature Reserve as indicator of their overall view of the protected areas.

A large proportion of respondents manifested negative attitude toward Dwesa-Cwebe Nature Reserve stating that they are either "Not at all satisfied" or Very Satisfied with Dwesa-Cwebe Nature Reserve. The communities adjacent to DwesaCwebe nature reserve are not at all satisfied with overall idea of the nature reserve. They fell like they are taken for granted by the management of the reserve and they are not involved in the decision making of the nature reserve. Moreover differences in attitude exist not only due to differences in awareness and concern but also due to the different use types people associate with the protected area. The results of the study show that there is a significant correlation between community perceptions of conservation of nature and tourism at Dwesa-Cwebe Nature Reserve and level of education, household sizes, or level of income in all three communities. The most disadvantaged families are the one mostly in need of resources that are located inside the boundaries of the Nature Reserve.

\section{Conclusion}

The study found out that removing local community from the lands that they have been exploiting for generation without consultation or compensation has resulted in negative attitude towards the protected areas objectives. One of the most important general strategies for developing local community acceptance of protected areass may be community participation in protected areas management. The conflicts between the conservationists and people desperate for access to land and natural resources have caused widespread criticism of conservation of biodiversity and their activities in Dwesa-Cwebe Nature Reserve. The research concluded that these conflicts between these two parties are as a result of the lack of community participation in the conservation activities. Local protected areas are an important resource for policy makers and can be a benefit or a burden to local population if they are not involved.

\section{References}

[1] G. S. M. Andrade, J. R. Rhodes, "Protected Areas and Local Communities: A inevitable partnership towards successful conservation strategies?," Ecology and Society, 2012. 
[2] E. Barrow, M. Murphree, Community Conservation from Concept to Practice, In African Wildlife and Livelihoods: the Promise and Performance of Community Conservation. James Currey: Oxford, United Kingdom, 2001.

[3] G. Borrini-Feyerabend, A. Kothari, G. Oviedo Indigenous and Local communities and Protected Areas: towards Equity and Enhanced Conservation. IUCN, Gland, Switzerland and Cambridge UK, 2004.

[4] J. MacKenzie, National Parks in Africa and Asia, in the Empire of Nature: Hunting, Conservation and British Imperialism. Manchester University Press, 1988.

[5] J. E. Mbaiwa, "Wildlife Resource Utilization at Moremi Game Reserve and Khwai Community Area in the Okavango Delta, Botswana," Journal of Environmental Management, vol. 77, pp. 144-156, 2005.

[6] A. R. Mugisha, Evaluation of Community-Based Conservation Approaches: Management of Protected Areas in Uganda University of Florida, 2002.

[7] H. P. Shikolokolo, An Evaluation of the Impact of Kruger National Park's Development Programme on the Hlanganani Community in the Limpopo Province. Masters of Development, University of Limpopo, 2010.

[8] M. E. Tessema, R. J. Litcholm, Z. T. Ashenafi, N. Leader-Williams, "Community Attitudes toward Wildlife and Protected Area in Ethiopia," Society and National Resources, vol. 23, pp. 489-506, 2010.

[9] K. Tunley, State of Management of South Africa's Marine Protected Areas. WWF South Africa Report Series2009/Marine/001, 2009.

[10] K. Tunley, State of Management of South Africa's Marine Protected Areas. WWF South Africa Report Series2009/Marine/001, 2009.

[11] United Nation Environment Programme, Global Environment Outlook 3. Earthscan: Publications, UK, 2002. 